\title{
Chloroquine promotes gefitinib-induced apoptosis by inhibiting protective autophagy in cutaneous squamous cell carcinoma
}

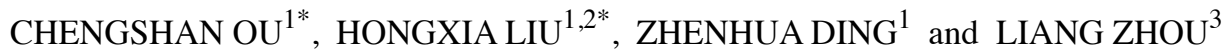 \\ ${ }^{1}$ Department of Radiation Medicine, Guangdong Provincial Key Laboratory of Tropical Disease Research, School of \\ Public Health, Southern Medical University, Guangzhou, Guangdong 510515; ${ }^{2}$ Institute of Radiation Medicine, \\ Fudan University, Shanghai 200032; ${ }^{3}$ Department of Toxicology, Guangdong Provincial Key Laboratory of Tropical \\ Disease Research, School of Public Health, Southern Medical University, Guangzhou, Guangdong 510515, P.R. China
}

Received November 8, 2018; Accepted July 26, 2019

DOI: $10.3892 / \mathrm{mmr} .2019 .10734$

\begin{abstract}
Aberrant expression of the epidermal growth factor receptor (EGFR) plays vital roles in tumor development and progression. In the present study, ultraviolet irradiation induced the upregulation of EGFR in skin-derived keratinocytes, which may contribute to the development of cutaneous squamous cell carcinoma (CSCC). This was supported by the high expression of EGFR in CSCC clinical samples. Treating A431 CSCC cells with gefitinib, a tyrosine kinase inhibitor, activated the intrinsic mitochondrial apoptotic pathway while inducing protective autophagy. Combined application of chloroquine with gefitinib enhanced the treatment efficacy of gefitinib against CSCC by inhibiting autophagic flux. These findings demonstrated that autophagy inhibition may be an effective strategy for enhancing the sensitivity of EGFR-expressing cells to tyrosine kinase inhibitor treatment. Manipulating pro-survival autophagy by the combined application of chloroquine with gefitinib is a promising approach for improving the efficacy of EGFR inhibitors in cancer treatment. This may contribute to novel EGFR-targeted therapeutic strategies in the near future.
\end{abstract}

\section{Introduction}

Cutaneous squamous cell carcinoma (CSCC) is the second most common cancer with an annual incidence of over one million worldwide (1). CSCC develops mainly in skin with chronic

Correspondence to: Professor Liang Zhou, Department of Toxicology, Guangdong Provincial Key Laboratory of Tropical Disease Research, School of Public Health, Southern Medical University, 1838 Northern Guangzhou Avenue, Guangzhou, Guangdong 510515, P.R. China

E-mail: zhzliang@smu.edu.cn

*Contributed equally

Key words: gefitinib, epidermal growth factor receptor, chloroquine, apoptosis, autophagy sun exposure. Ultraviolet (UV) radiation is considered to be the major cause of CSCC due to UV-induced DNA damage and epigenetic changes (2). In response to UV radiation, skin cells activate several pathways including mitogen-activated protein kinase (MAPK), phosphoinositide 3-kinase (PI3K), extracellular signal-regulated kinase (ERK), p38 kinase, and c-Jun N-terminal kinase (JNK) signaling cascades $(3,4)$. These pathways can promote tumorigenesis at an early stage, and facilitate the development of CSCC to a poorly differentiated cancer. Furthermore, metastases can eventually develop in the lymph system or other organs (5).

For invasive CSCC, surgical excision and Mohs micrographic surgery are typically the primary treatment options (6). Chemotherapy is considered to be adjuvant therapy to block the aforementioned pro-carcinogenic pathways in select high risk cases of CSCC to provide improved locoregional control (5). The selection of appropriate targets is critical for the success of chemotherapy.

The epidermal growth factor receptor (EGFR), an activator of MAPK and PI3K pathways, is stimulated upon exposure to UV radiation (2). Blockade of the EGFR inhibits the subsequent activation of EGFR downstream signaling cascades and makes EGFR the optimal target for cancer therapy, including CSCC $(5,7)$. Among the various EGFR inhibitors, gefitinib (ZD1839) is a selective EGFR tyrosine kinase inhibitor with a significant beneficial effect in various cancers $(8,9)$. Cell death induced by gefitinib is one of the major mechanisms by which it inhibits cancer development. Apoptosis, type I programmed cell death, was considered to be one of the most promising antitumor mechanisms in cancer therapy. However, inherent and acquired resistance to apoptosis play crucial roles in tumor development and treatment failure. Therefore, novel strategies are essential to improve treatment efficiency.

Autophagy, an evolutionarily conserved catabolic process, sequesters proteins and damaged organelles into autophagosomes, then fuses them with lysosomes to form autolysosomes for bulk degradation of embedded materials (7). The role of autophagy is debatable and has special importance in cancer research. Primarily, autophagy is defined as type II programmed cell death (10). It is considered to be an alternative tumor-suppressing mechanism induced by genomic instability, suppression of cell growth, and degradation of 
vital components (11). However, recycled proteins and other components, along with the energy saved, contribute to the maintenance of cellular homeostasis and support tumor cell survival under stressed circumstances $(9,11)$. Therefore, the role of autophagy is complicated and may lead to diametrically opposed consequences: tumor survival or death.

In this study, the tumor-suppressive role of gefitinib was evaluated in A431 CSCC cells that are recognized for their high expression of EGFR. Gefitinib treatment strongly suppressed the proliferation and invasion of CSCC cells by targeting EGFR to induce apoptosis and autophagy. Co-treatment of these cells with gefitinib and chloroquine inhibited protective autophagy and enhanced apoptosis, thereby improving the therapeutic response of CSCC cells.

\section{Materials and methods}

Ethics statement. The present study was approved by the Institutional Review Board of Nanfang Hospital, affiliated to Southern Medical University. All patients provided written informed consent for the use of surgical samples. This study was conducted in accordance with the World Medical Association Declaration of Helsinki.

Cell culture and tumor samples. The CSCC cell line, A431 (China Center for Type Culture Collection and Cell Bank of the Chinese Academy of Sciences, Shanghai, China), and the human benign epidermal keratinocyte cell line, HaCaT (China Center for Type Culture Collection, Wuhan, China), were cultured in Dulbecco's modified Eagle medium (DMEM) supplemented with $10 \%$ fetal bovine serum, $100 \mathrm{U} / \mathrm{ml}$ penicillin, and streptomycin (Invitrogen; Thermo Fisher Scientific, Inc.), and maintained at $37^{\circ} \mathrm{C}$ with $5 \% \mathrm{CO}_{2}$ in a humidified atmosphere. Twenty normal (age range from 25 to 67 ) and 20 CSCC (age range from 29 to 65) samples were obtained from patients diagnosed with CSCC from January 2009 to August 2011 at the departments of Dermatology, Pathology and Oncology at Nanfang Hospital and Zhujiang Hospital, affiliated to Southern Medical University, and The Third Affiliated Hospital to Sun Yat-sen University.

$U V$ irradiation. HaCaT cells were irradiated when grown to $\sim 80-90 \%$ confluence. Prior to UVB exposure $\left(30 \mathrm{~mJ} / \mathrm{cm}^{2}\right)$, cells were washed twice with phosphate-buffered saline (PBS) and covered with a thin layer of PBS. In parallel, non-irradiated cells were treated similarly and maintained in the dark in an incubator. The UVB light source was produced by Shanghai Gucun Electro-Optical Instrument Factory. The dose rate was assessed by Shanghai Institute of Measurement and Testing Technology. The wavelength peak of the UVB lamp used was $305 \mathrm{~nm}$, and the power density was $16.5 \mu \mathrm{W} / \mathrm{cm}^{2}$.

Drug treatment. Gefitinib (cat. no. S1025) was purchased from Selleck Chemicals. Chloroquine (cat. no. A506569) was obtained from Sangon Biotech Co., Ltd. Various concentrations $(0.1,1,10,50$ and $100 \mu \mathrm{M})$ of gefitinib, alone or combined with chloroquine, were added to the cells at the indicated time-points at $37^{\circ} \mathrm{C}$ with $5 \% \mathrm{CO}_{2}$ in a humidified incubator. Then, cellular proteins were collected for further analysis. 3-Methyladenine (3-MA), an autophagy (PI3K) inhibitor, was used at $5 \mathrm{mM}$ to evaluate the accumulation of LC3-II induced by gefitinib.

Immunoblotting and immunohistochemistry (IHC) assays. Total cell extracts were prepared and assayed by western blotting as previously described (12), with minor modifications. Briefly, total cellular proteins $(20 \mu \mathrm{g})$ were electrophoresed through a $10 \%$ denaturing polyacrylamide gel and transferred to a nitrocellulose membrane (Schleicher \& Schuell BioScience, Inc.). The blots were probed with the following primary antibodies and dilutions: LC3-II (Cell Signaling Technology, Inc., 3868, 1:2,000), and p62 (Santa Cruz Biotechnology, Inc., sc-25575, 1:5,000), GAPDH (Santa Cruz Biotechnology, Inc., sc-32233, 1:5,000), caspase-3 (Santa Cruz Biotechnology, Inc., sc-7148, 1:5,000), phospho (p)-EGFR (Tyr 1173) (Santa Cruz Biotechnology, Inc., sc-101668, 1:2,000), and EGFR (Cell Signaling Technology, Inc., 4267, 1:2,000). Anti-mouse IgG-horseradish peroxidase (HRP) (Thermo Scientific, Inc., 31430, 1:5,000) and anti-rabbit IgG-HRP (Thermo Scientific, Inc., 31460, 1:5,000) were used as secondary antibodies. Bound antibodies were visualized with the Luminata Forte Western HRP substrate (EMD Millipore) according to the manufacturer's protocol. Densimetric quantification of the western bands was performed using Quantity One software (Bio-Rad Laboratories, Inc.) and presented as histograms.

IHC staining on formalin-fixed paraffin-embedded CSCC sections, were performed using EGFR (1:100) and p-EGFR (1:100). At least 10 representative images of all IHC stained sections were captured using an Olympus IX51 microscope (Olympus Corporation) for statistical analysis.

RNA isolation and the quantitative real-time polymerase chain reaction. Total RNA from cells was extracted using TRIzol reagent (Life Technologies; Thermo Fisher Scientific, Inc.) according to the manufacturer's instructions. cDNAs were prepared using Moloney murine leukemia virus reverse transcriptase (Life Technologies; Thermo Fisher Scientific, Inc.) and an oligo(dT)20 primer. mRNA expression analysis was performed using SYBR Green Master Mix (Life Technologies; Thermo Fisher Scientific, Inc.) on a LightCycler 96 Detection System (Roche Diagnostics) using GAPDH for normalization. The cycling parameters were: $95^{\circ} \mathrm{C}$ for $10 \mathrm{~min}$, followed by 40 cycles at $95^{\circ} \mathrm{C}$ for $15 \mathrm{sec}$ and an annealing/extension step at $60^{\circ} \mathrm{C}$ for $40 \mathrm{sec}$. The primer pairs used in this study were: $\mathrm{N}$-cadherin (F: 5'-ATCCTCCAGAGTTTACTGCCATGA-3' and R: 5'-TGCAGCAACAGTAAGGACAAACA-3'); vimentin (F: 5'-AAGAGAACTTTGCCGTTGAAGCT-3' and R: 5'-CCT CAGGTTCAGGGAGGAAAA-3'); glyceraldehyde 3-phosphatedehydrogenase (GAPDH) (F: 5'-TTGCCATCAATGACC CCTTCA-3' and R: 5'-CGCCCCACTTGATTTTGGA-3'). The fold change was calculated by the $2^{-\Delta \Delta C q}$ method (13). All experiments were performed in triplicate.

Cell viability assay. Crystal violet staining was used to measure cell viability in cultures as previously described (14). In this procedure, the attached cells are stained with crystal violet that binds to proteins and DNA. Dead cells lose their adherence and are subsequently washed away from the population of cells. This reduces the amount of crystal violet staining in the culture. At least 10 representative bright field images 
of randomly selected fields were captured using an Olympus IX51 microscope for statistical analysis.

Wound healing assay. Cells were seeded into six-well plates and allowed to form confluent monolayers. Then, the cells were exposed to various concentrations $(0,50$ and $100 \mu \mathrm{M})$ of agents. Next, the monolayers were scratched horizontally using a sterile 200- $\mu$ l pipette tip. Cells were washed with PBS and cultured in DMEM. Progression of migration was observed and images were captured at $0,3,6$, and $9 \mathrm{~h}$ after wounding.

Cell invasion and migration assays. Cells were plated on the top side of an uncoated or Matrigel-coated polycarbonate Transwell filter in the upper chamber and incubated at $37^{\circ} \mathrm{C}$ for $\sim 12-16 \mathrm{~h}$, followed by the removal of cells inside the upper chamber with a cotton swab. Migrated and invaded cells on the lower membrane surface were fixed in $4 \%$ paraformaldehyde for $10 \mathrm{~min}$ at room temperature and stained with $0.1 \%$ crystal violet for $5 \mathrm{~min}$ at room temperature. The number of migrated or invading cells was counted in five fields under an x200 magnification.

Colony formation assay. Exponentially growing cells were collected by trypsinization and plated at a low density (500 cells/plate). Various concentrations $(0,10$ and $20 \mu \mathrm{M})$ of gefitinib were then added in complete DMEM for 6 days. Colonies were fixed in $1 \%$ crystal violet (w/v) in $100 \%$ methanol for $20 \mathrm{~min}$ and then counted visually.

Cell Counting Kit (CCK)-8 cell proliferation assay. Cells were plated in triplicate in 96 -well plates at a density of $8 \times 10^{3}$ cells/well. After $24 \mathrm{~h}$, the cells were placed in complete DMEM containing the indicated drug concentrations, or vehicle control. Then, the plates were incubated at $37^{\circ} \mathrm{C}$. After $12 \mathrm{~h}$, each well was incubated with $100 \mu \mathrm{l}$ DMEM containing $10 \mu \mathrm{l}$ CCK- 8 reagent. After $1 \mathrm{~h}$, the absorbance was measured at $450 \mathrm{~nm}$ using a microplate reader (Bio-Rad Laboratories, Inc.).

Apoptosis analysis. A431 cells were treated with the indicated concentrations $(0.1,1,10,50$ and $100 \mu \mathrm{M})$ of gefitinib. Trypsinized cells were collected and washed with cold PBS. The cells were then collected and resuspended in $50 \mu \mathrm{l}$ of binding buffer containing $2.5 \mu \mathrm{l}$ of Annexin V-fluorescein isothiocyanate and $2.5 \mu \mathrm{l}$ of propidium iodide. After incubation for $15 \mathrm{~min}$ in the dark at room temperature, $200 \mu \mathrm{l}$ buffer were added to the solution. Fluorescence was measured on a flow cytometer and analyzed using ModFit software (version 3.1, Verity Software House, Inc.).

Morphologic analysis by electron microscopy. Transmission electron microscopic analysis is considered the gold standard in cell death research. Cells were harvested by trypsinization, washed with PBS, then fixed with a solution containing $2.5 \%$ glutaraldehyde in PBS for at least $1 \mathrm{~h}$ at $4^{\circ} \mathrm{C}$. The samples were rinsed three times for $15 \mathrm{~min}$ each in $0.1 \mathrm{M}$ cacodylate buffer containing $7.5 \%$ sucrose, and fixed in $1 \%$ osmium in cacodylate buffer for $1 \mathrm{~h}$. After being washed three times in $0.11 \mathrm{M}$ veronal acetate buffer for $15 \mathrm{~min}$ each, the samples were incubated with $0.5 \%$ uranyl acetate in veronal acetate buffer for $1 \mathrm{~h}$ at room temperature. Specimens were then dehydrated in an ascending series of ethanol $(35,70$, and $95 \%$, then twice with $100 \%$ ) for $10 \mathrm{~min}$ each, followed by two changes of propylene oxide for $5 \mathrm{~min}$ each. The samples were incubated with a 1:1 mixture of $100 \%$ resin and propylene oxide for $1 \mathrm{~h}$, followed by two changes of $100 \%$ resin, each for $30 \mathrm{~min}$. Finally, the samples were embedded in resin and polymerized at $60^{\circ} \mathrm{C}$ overnight. Areas containing cells were block mounted and cut into $70-\mathrm{nm}$ sections. The sections were stained with uranyl acetate and lead citrate. Finally, the ultrathin sections were examined under a transmission electron microscope.

Autophagy analysis by acridine orange $(A O)$ staining. $\mathrm{AO}$ is a cell-permeable green fluorophore that can be trapped and fluoresce red in acidic vesicular organelles (AVOs); i.e., autolysosomes. This feature makes AO staining a quick and reliable method to evaluate the volume of AVOs, which significantly increase during the induction of autophagy. AO staining was performed as previously described (15). Specifically, the cells were stained with $1 \mu \mathrm{g} / \mathrm{ml} \mathrm{AO}$ for $15 \mathrm{~min}$, and then examined under a fluorescence microscope.

Statistical analysis. Data are presented as the mean \pm standard deviation. Groups were compared by a one-way analysis of variance using the SNK-q test, or by t-test with a two-tailed P-value. The expression levels of proteins were analyzed by ANOVA based on the value of densimetric quantification of the western bands. All statistical tests were considered to reflect significant differences if $\mathrm{P}<0.05$.

\section{Results}

EGFR is induced by $U V$ irradiation and is highly expressed in CSCC cells and tumors. UV radiation is one of the major causal stimulators leading to CSCC (6). To gain insights into the molecular events within skin cells after exposure to UV radiation, HaCaT keratinocytes were treated with $30 \mathrm{~mJ} / \mathrm{cm}^{2}$ UVB. Western blotting revealed that the expression of EGFR was induced by UVB irradiation (Fig. 1A).

The A431 cell line features an unusual EGFR gene amplification (8) that contributes to the markedly higher expression of EGFR in these cells than HaCaT keratinocytes (Fig. 1B). To determine whether EGFR expression was also dysregulated in CSCC tumors, EGFR was detected in 20 normal and 20 CSCC tumor sections by IHC. The results confirmed the presence of high levels of EGFR protein in CSCC tumors (Fig. 1C). Collectively, these results indicated that the induction of EGFR by UV exposure may be involved in causing CSCC.

Gefitinib inhibits the activation of EGFR. Since EGFR is highly upregulated in CSCC cells, treatments designed to inhibit its activity are considered to be useful. Gefitinib inhibits the EGFR tyrosine kinase domain by binding to the ATP binding site of the enzyme thereby inhibiting the anti-apoptotic signal transduction cascade (16). To assess whether gefitinib functioned in CSCC cells, A431 cells were treated with $100 \mu \mathrm{M}$ gefitinib and the level of p-EGFR was probed by western blotting. By analyzing the ratio of $\mathrm{p}$-EGFR/total EGFR, the activation (phosphorylation) of EGFR was significantly suppressed by gefitinib treatment (Fig. 1D). 
A

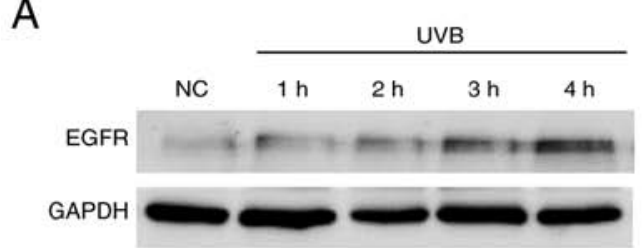

C

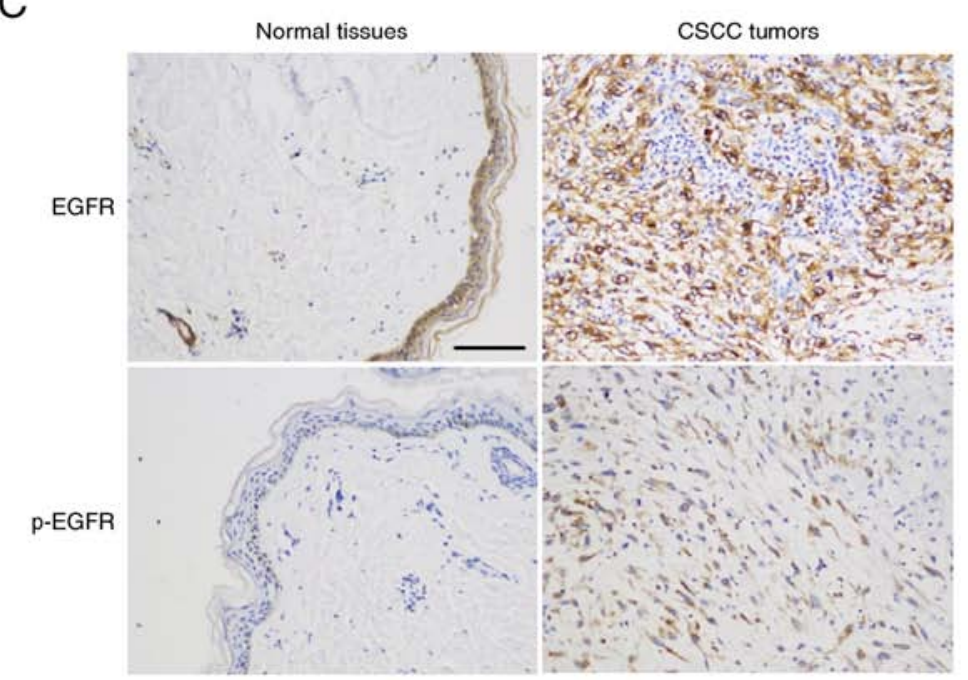

B
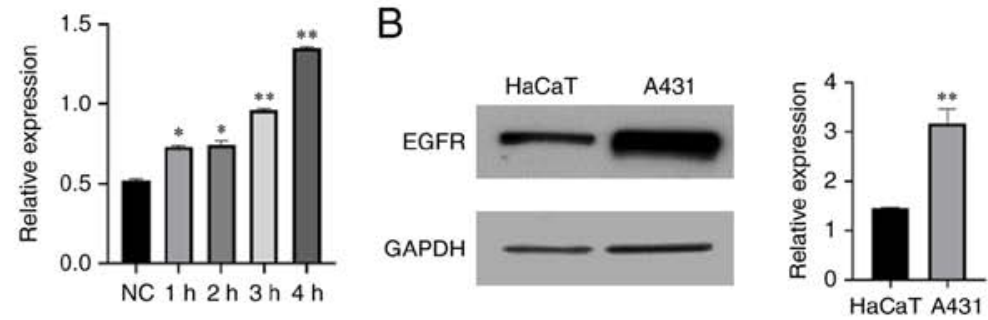

D
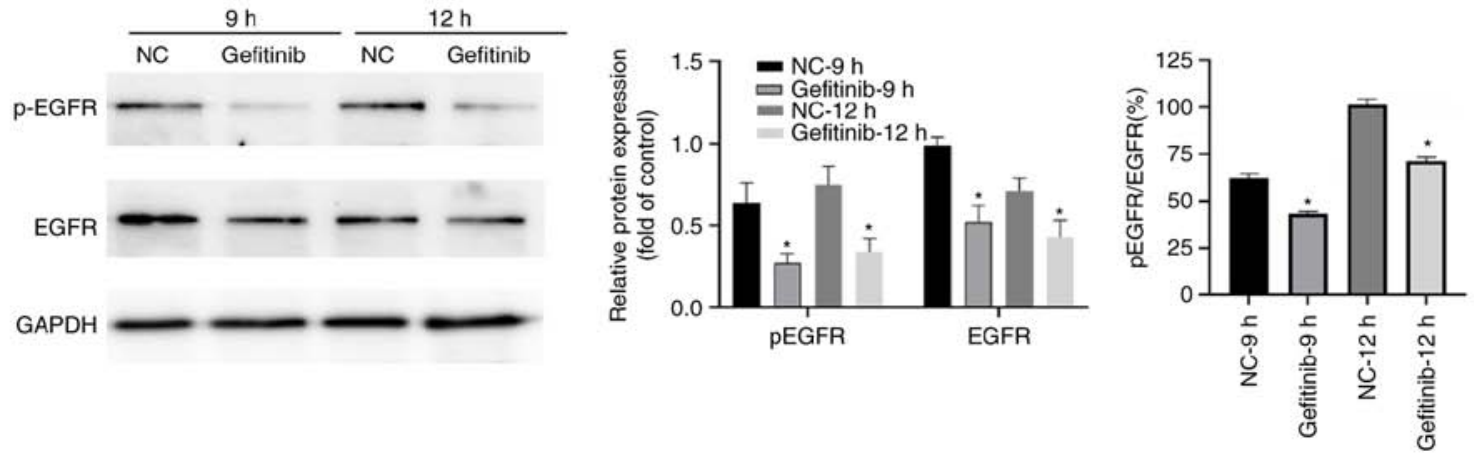

Figure 1. Expression of EGFR in CSCC. (A) HaCaT cells were exposed to UVB $\left(30 \mathrm{~mJ} / \mathrm{cm}^{2}\right)$ irradiation at indicated time-points and then the expression levels of EGFR were detected using western blot analysis. ${ }^{*} \mathrm{P}<0.05,{ }^{* *} \mathrm{P}<0.01$ vs. NC. GAPDH served as the loading control. (B) EGFR and GAPDH in human $\mathrm{HaCaT}$ and $\mathrm{A} 431$ cell lines were detected by western blotting. ${ }^{* *} \mathrm{P}<0.01 \mathrm{vs}$. HaCaT (C) IHC detection of EGFR expression in human normal skin and CSCC tissues ( $\mathrm{n}=20)$ (scale bar, $100 \mu \mathrm{m}) .{ }^{* *} \mathrm{P}<0.01$ (D) A431 cells were treated with gefitinib $(100 \mu \mathrm{M})$ for 9 or $12 \mathrm{~h}$, and p-EGFR EGFR and GAPDH were immunoblotted using appropriate antibodies. " $\mathrm{P}<0.05$ vs. NC-9 h. EGFR, epidermal growth factor receptor; CSCC, cutaneous squamous cell carcinoma; IHC, immunohistochemistry.

Gefitinib treatment strongly inhibits the proliferation, mobility, and invasiveness of CSCC cells. To investigate the cellular effects of gefitinib, the capacities of proliferation, mobility, and invasiveness of CSCC cells were explored. Cell proliferation was assessed by both the CCK-8 assay and crystal violet staining. The results revealed that gefitinib significantly suppressed the proliferation of A431 cells (Fig. 2A and B). The colony formation assay revealed that there were significantly fewer colonies formed in the gefitinib-treated group compared to the control cells that formed relatively large and numerous colonies (Fig. 2C).

The mobility of CSCC cells was evaluated by wound healing and Transwell migration assays. The mobility of A431 cells was significantly inhibited by gefitinib treatment (Fig. 2D). The Transwell assay revealed that the invasiveness of CSCC cells was also significantly suppressed by gefitinib (Fig. 2E). To further address the effects of gefitinib on cellular migration and invasiveness, the expression of the cellular adhesion and migration markers $\mathrm{N}$-cadherin and vimentin, were assessed, Their expression was decreased with increasing concentrations of gefitinib (Fig. 2F). These findings demonstrated that gefitinib inhibits various malignant capacities of CSCC cells.

Gefitinib treatment induces apoptosis as well as autophagy in CSCC cells. To explore the mechanism underlying the inhibition of malignant features in CSCC cells treated with gefitinib, its apoptotic effects were examined. Annexin/propidium iodide double staining followed by flow cytometry revealed enhanced apoptosis induced by gefitinib treatment (Fig. 3A and B). To confirm the apoptosis-inducing role of gefitinib, the apoptotic 
A

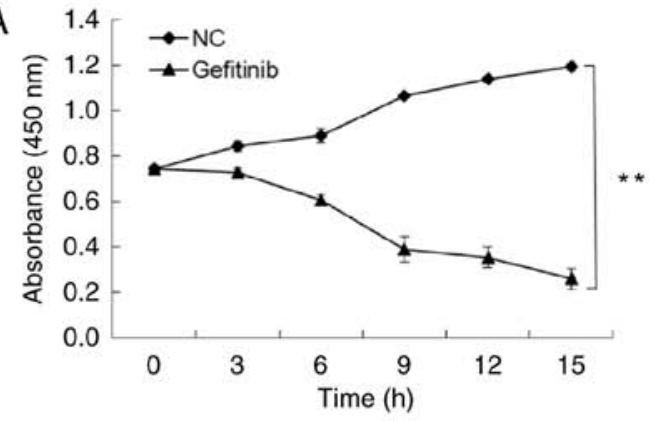

B

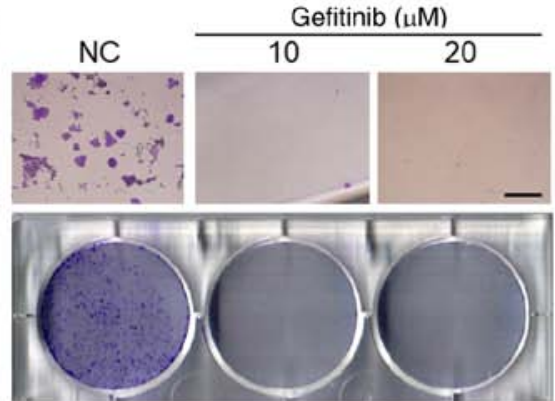

C Time (h)

3

6

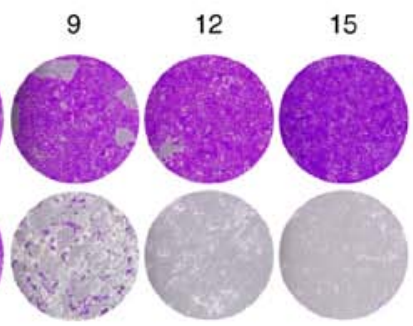

D
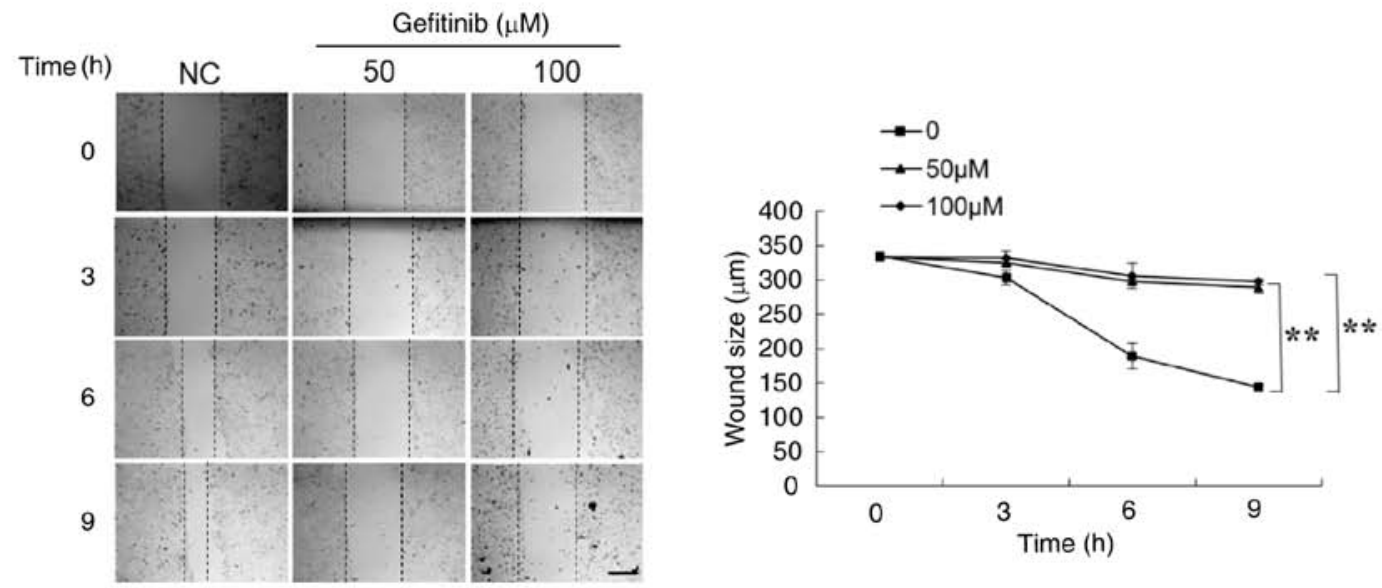

$E$
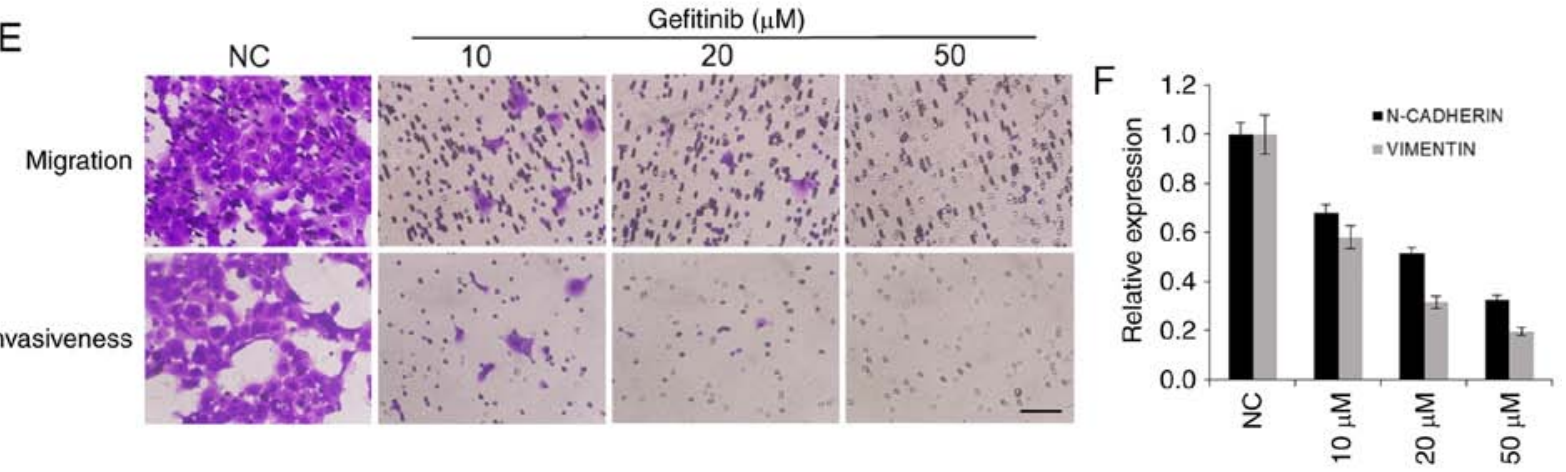

Figure 2. Gefitinib treatment suppresses the proliferation, mobility and invasiveness of CSCC cells. (A) The proliferation ability of A431 cells treated with gefitinib $(100 \mu \mathrm{M})$ was assessed by CCK-8 assays. (B) The representative images of crystal violet-stained cell colonies in A431 cells treated with gefitinib $(10$ or $20 \mu \mathrm{M})$ are presented (scale bar, $50 \mu \mathrm{m})$. (C) Colony formation ability of A431 cells following treatment with gefitinib (100 $\mu \mathrm{M})$ or with DMSO as a control for different time-points. (D) The effect of gefitinib (50 or $100 \mu \mathrm{M})$ on A431 cell mobility for indicated time-points is presented (scale bar, $100 \mu \mathrm{m})$. (E) Invasive and migratory capacities of A431 cells treated with gefitinib $(10,20$, or $50 \mu \mathrm{M})$ or with DMSO as a control were detected by Matrigel-coated or Matrigel-non-coated Transwell assays, respectively (scale bar, $50 \mu \mathrm{m}$ ). (F) qPCR analysis of the expression of $\mathrm{N}$-cadherin and vimentin. ${ }^{* *} \mathrm{P}<0.01$. CSCC, cutaneous squamous cell carcinoma.

phenotype wa $\sigma$ observed directly by transmission electron microscopy. Clear condensation and apoptotic body formation was observed in $>50 \%$ of A431 cells treated with gefitinib (Fig. 3C). Notably, autophagosomes, direct evidence of ongoing autophagy, were widely distributed in the cells (Fig. 3D). The time-dependent enhancement of autophagy by gefitinib in A431 cells was supported by AO staining (Fig. 3E). Western blot results revealed not only time-dependent enhanced cleavage of caspase-3 and caspase-9 (which marked the development of apoptosis upon gefitinib treatment), but also gradually increasing 
A Gefitinib

$(\mu \mathrm{M})$
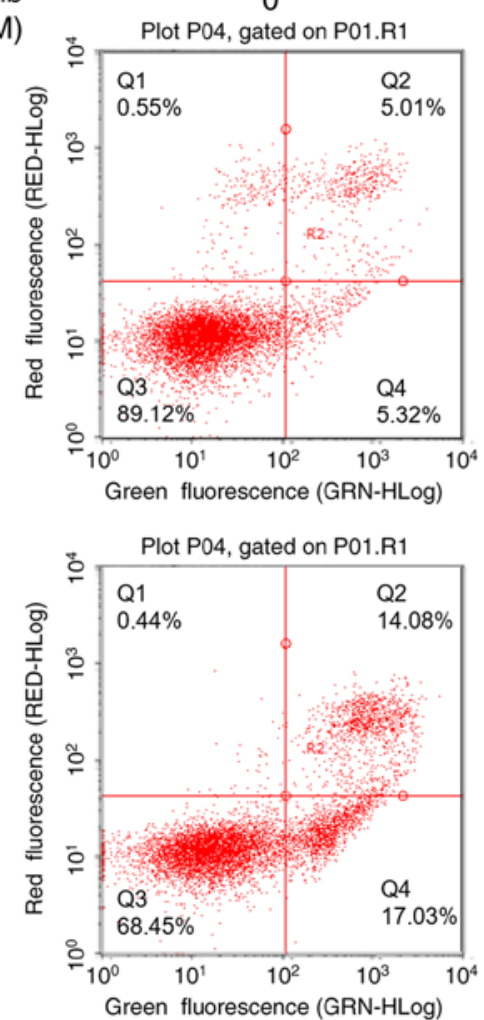

10
0.1
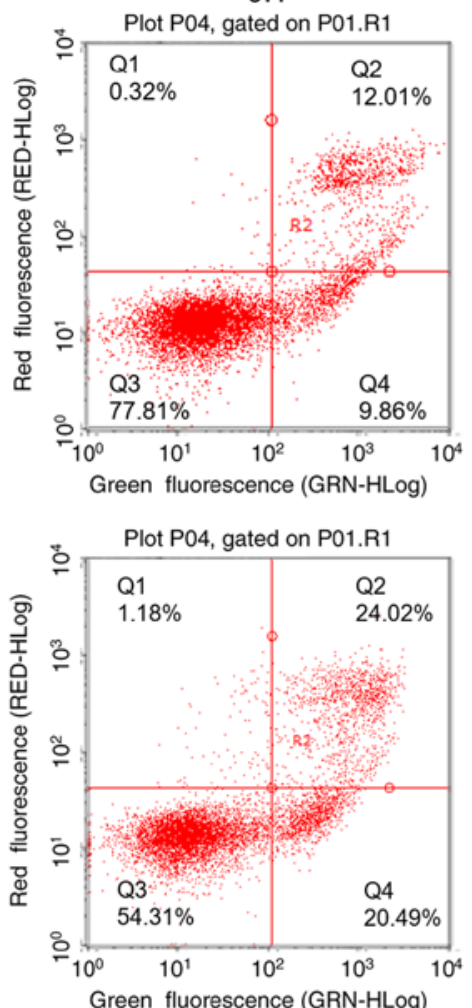

50
1
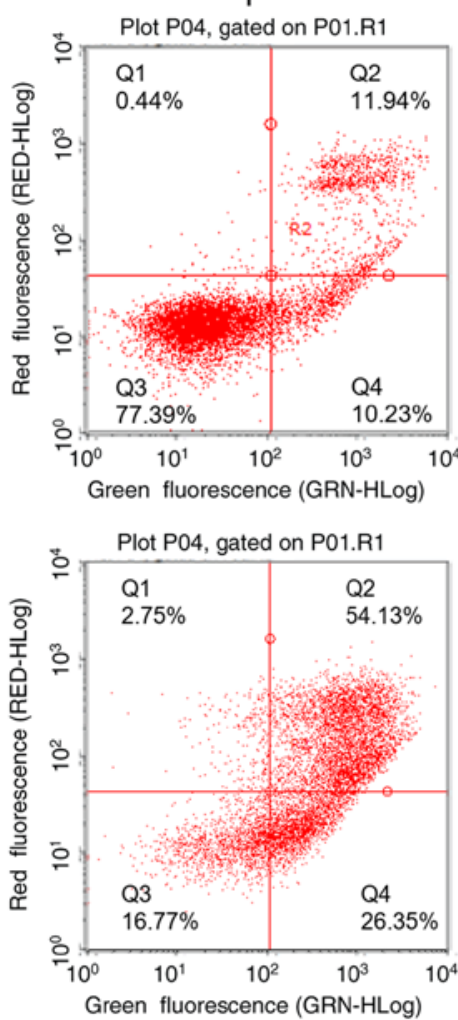

100

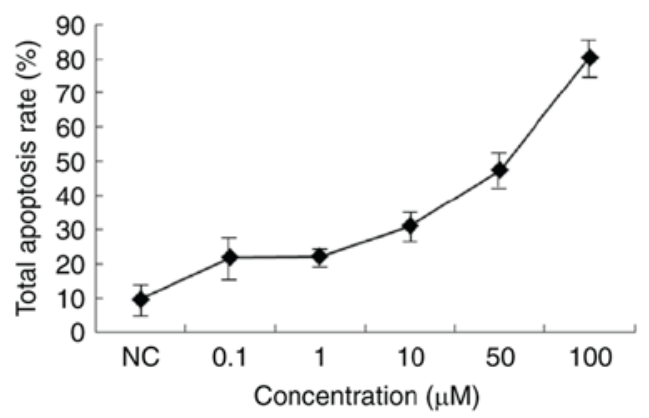

Figure 3. Gefitinib treatment can induce apoptosis and autophagy in CSCC cells. (A) A431 cells were treated with indicated concentrations of gefitinib for $12 \mathrm{~h}$ and then the total cell apoptosis rate was analyzed by flow cytometric analysis. CSCC, cutaneous squamous cell carcinoma.

autophagy indicated by an increased level of LC3-II (Fig. 3F). Furthermore, treatment of these cells with 3-MA, an autophagy (PI3K) inhibitor, suppressed the accumulation of LC3-II induced by gefitinib (Fig. 3G). These results indicate both apoptosis and autophagy are induced by gefitinib treatment.

Inhibition of the autophagy by chloroquine promotes gefitinib-induced apoptosis. Autophagy is recognized as a survival mechanism in cancer cells $(9,12)$. In contrast, autophagy is also considered to be type II programmed cell death (11). To assess the precise role of gefitinib-induced autophagy (i.e., survival or death), chloroquine, which can block the fusion of autophagosomes with lysosomes and thus disrupt autophagic flux, was used to selectively inhibit autophagy induced by gefitinib. Treatment of A431 cells with chloroquine alone suppressed their proliferation, migration, and invasiveness to some extent (Fig. 4A and B) while promoting apoptosis (Fig. 4C). Notably, co-treatment of A431 cells with both gefitinib and chloroquine suppressed their proliferation, mobility, and invasiveness to a greater extent than either agent alone, and in a concentration-dependent manner (Fig. 4A and B). Chloroquine also concentration-dependently promoted gefitinib-induced apoptosis (Fig. 4D). The concentration-dependent enhancement of apoptosis and inhibition of autophagic flux by chloroquine was also supported by the enhanced cleavage of caspase- 3 and the accumulation of LC3-II and SQSTM1 (p62) due to the blockade of autophagic flux (Fig. 4E).

\section{Discussion}

In the present study, the pro-apoptotic role of gefitinib in CSCC cells was validated and autophagy as a survival mechanism induced by gefitinib treatment was identified. The pro-survival autophagic flux can be blocked by using chloroquine to interfere with the fusion of autophagosomes with lysosomes. Based on our results, the combined usage of gefitinib with chloroquine was proposed to establish an efficient therapy for CSCC. 

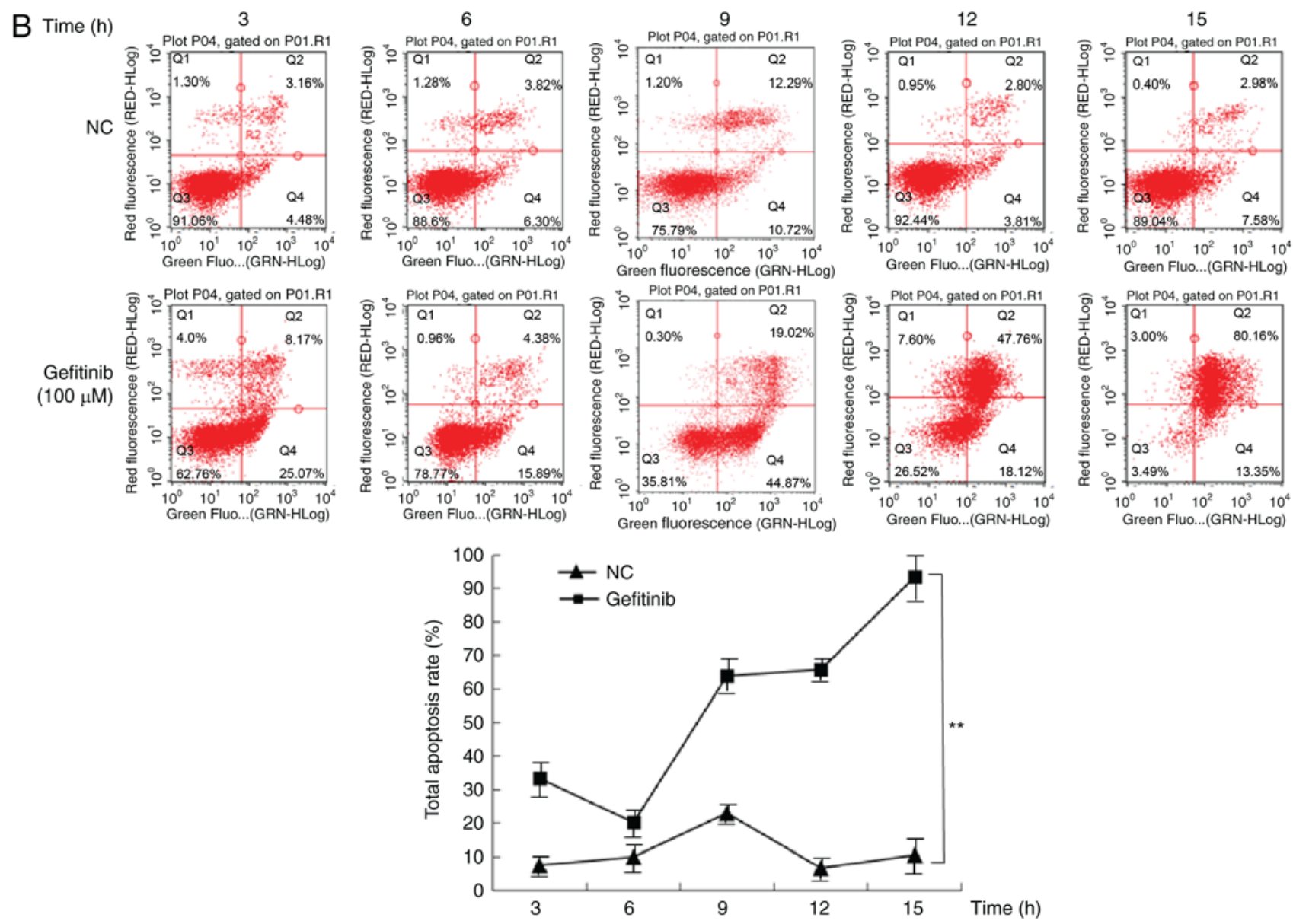

Figure 3. Continued. Gefitinib treatment can induce apoptosis and autophagy in CSCC cells. (B) A431 cells were treated with gefitinib (100 $\mu \mathrm{M})$ or with DMSO as a control and then the total cell apoptosis rate was assessed at various time-points by flow cytometric analysis. ${ }^{* *} \mathrm{P}<0.01$. CSCC, cutaneous squamous cell carcinoma.

EGFR, also known as human epidermal receptor 1 or ERBB1, is a transmembrane tyrosine kinase receptor that belongs to the human epidermal receptor family (17). Binding with its ligands, EGF or transforming growth factor- $\alpha$, can lead to conformational changes and homo- or hetero-dimerization. Subsequent autophosphorylation in the cytoplasmic tyrosine kinase domain triggers downstream signaling events. Due to its important roles in cell proliferation, differentiation, and inflammation, EGFR is regarded as a crucial focus of cell signaling pathways (18). In cancer, EGFR serves as a stimulus supporting cancer proliferation and tumor growth. Overexpression of the EGFR protein or mutations within its gene can activate downstream pro-carcinogenic pathways, especially in lung cancer (8).

Tyrosine kinase inhibitors (TKIs), including gefitinib, can inhibit the tyrosine kinase domain of EGFR reversibly by competitive binding to ATP, and are considered to cause tumor cell death through BIM-mediated apoptosis (19). Thus, TKIs have been widely used to treat cancers harboring aberrant expression of EGFR or EGFR mutations.

In a prospective phase II clinical trial, gefitinib was used as a neoadjuvant administered prior to standard treatment of surgery and/or radiotherapy to treat aggressive CSCC (5). Gefitinib was active and well-tolerated in these patients, and did not interfere with definitive treatments. An 18\% complete response rate was observed. Despite the success reported in that study, we continue to wait for new therapeutic advances using gefitinib as a neoadjuvant.

Non-small cell lung cancer (NSCLC) is closely associated with activating mutations of EGFR that activate pro-survival and anti-apoptotic signaling pathways, including Ras/Raf/MEK/MAPK, PI3K/AKT/mammalian target of rapamycin, and JAK/STAT (20). To induce the intrinsic mitochondrial apoptotic pathway, the specific EGFR TKI, gefitinib, has been approved by the United States Food and Drug Administration to treat advanced NSCLC with classical EGFR mutations. Nevertheless, most cases of NSCLC ultimately relapse within one year due to acquired resistance to EGFR TKIs (21). To enhance the pro-apoptotic effects of TKIs, methods of blocking the pro-survival pathway are under intensive study.

As a catabolic process, autophagy assures that cytosolic materials, including organelles, are sequestered into double-membrane autophagosomes and fuse with lysosomes for bulk degradation. The role of autophagy in the survival of cancer cells is unclear. As type II programmed cell death, autophagy may act as an alternative tumor-suppressing mechanism through the degradation of vital components, limiting cell growth and genomic instability (7). However, the recycling of proteins, organelles, and energy contributes to 


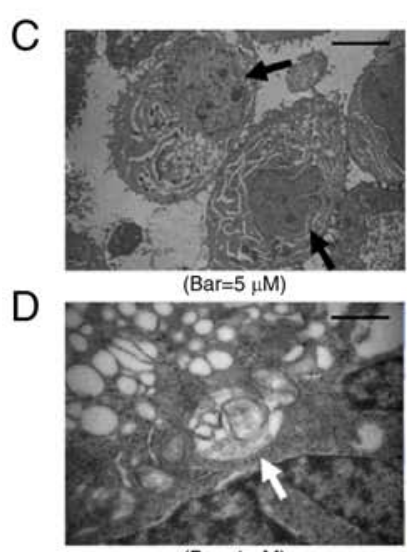

(Bar=1 $\mu \mathrm{M}$ )
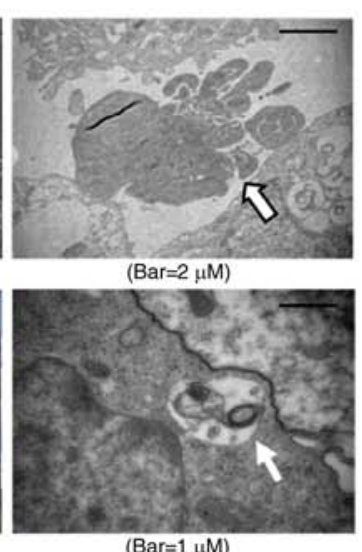

(Bar=1 $\mu \mathrm{M})$
E

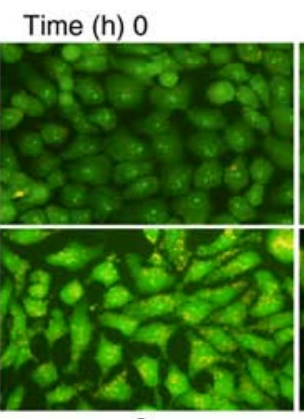

6

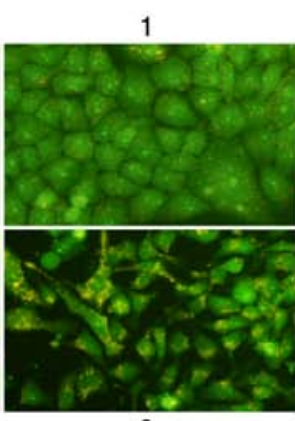

9

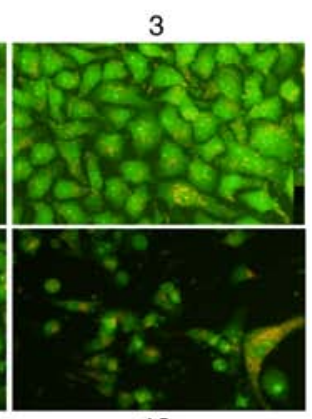

12

F
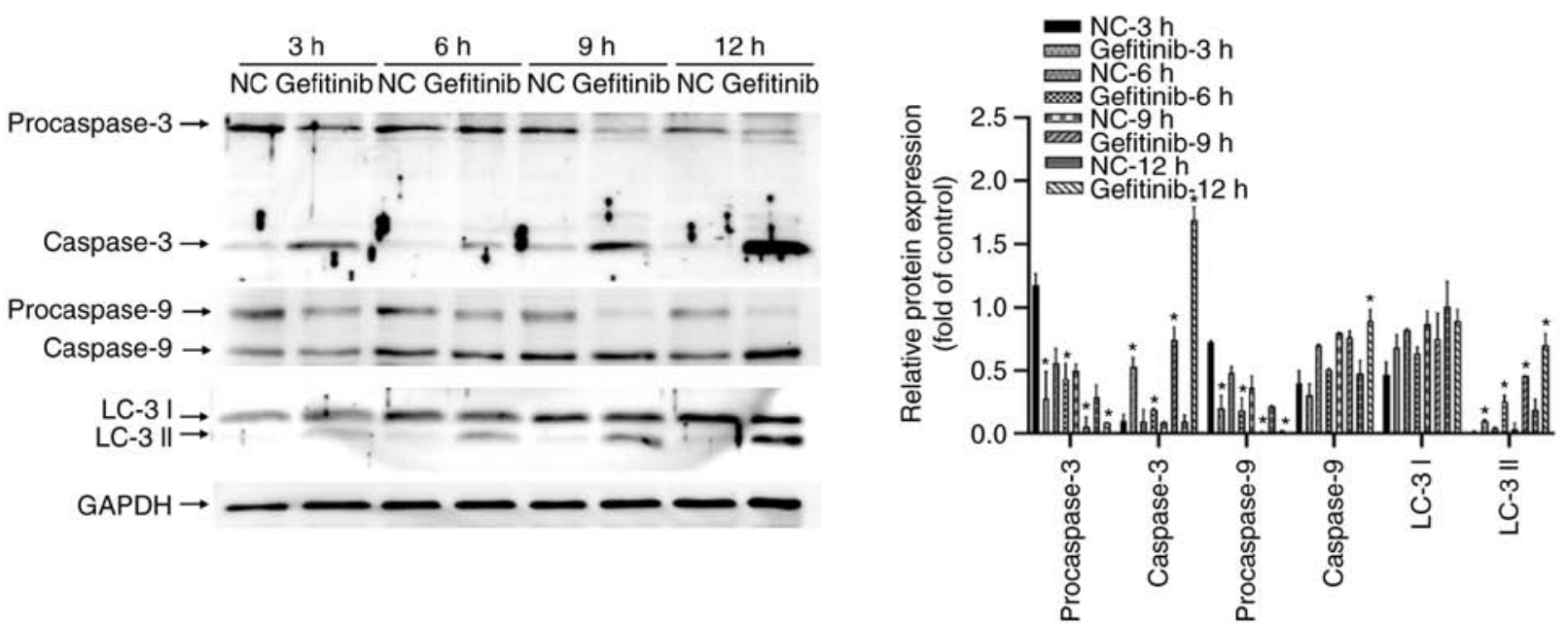

G
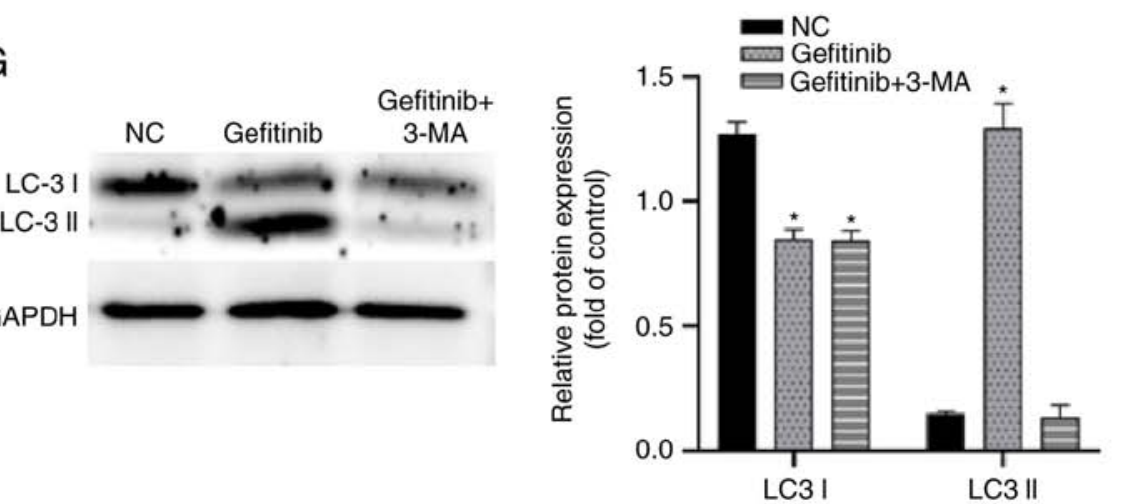

Figure 3. Continued. Gefitinib treatment can induce apoptosis and autophagy in CSCC cells. (C) A431 cells were incubated with gefitinib (100 $\mu \mathrm{M})$ for $12 \mathrm{~h}$, and then cellular apoptosis was observed using electron microscopy. Chromosomal condensation and apoptotic bodies were highlighted by arrows. (D) Cellular autophagy was detected by electron microscopy. Autophagic vacuoles containing organelle remnants were highlighted by arrows. (E) The autophagy in A431 cells following gefitinib (scale bar, $50 \mu \mathrm{M}$ ) treatment was analyzed by AO staining. (F) A431 cells were treated with gefitinib (100 $\mu \mathrm{M}$ ) or with DMSO as a control and then apoptosis and autophagy were monitored at various time-points by detecting caspase-3, caspase-9, and the total accumulation of LC3-II using western blotting analysis. GAPDH served as the loading control. "P<0.05 vs. NC-3 h. (G) LC3-II expression detected after gefitinib and 3-methyladenine (3-MA) treatments. " $\mathrm{P}<0.05$ vs. NC. CSCC, cutaneous squamous cell carcinoma.

the maintenance of cellular homeostasis and can promote the survival of cells (22). Thus, the role of autophagy in regulating cancer cell death or survival under different circumstances has not been fully explored (23).

In the present study, gefitinib was an effective TKI to induce apoptosis in CSCC cells. However, the accompanying induction of autophagy complicates the application of gefitinib. Currently, the activation of pro-survival autophagy as an early response to gefitinib treatment has been well-documented and functions as a protective mechanism to mediate resistance during anticancer therapy. This suggests using autophagy as a potential therapeutic target in cancer treatment $(23,24)$. To test this possibility, chloroquine was used to inhibit protective autophagy. This agent strongly suppressed autophagic flux and enhanced gefitinib-induced apoptosis in CSCC cells. 


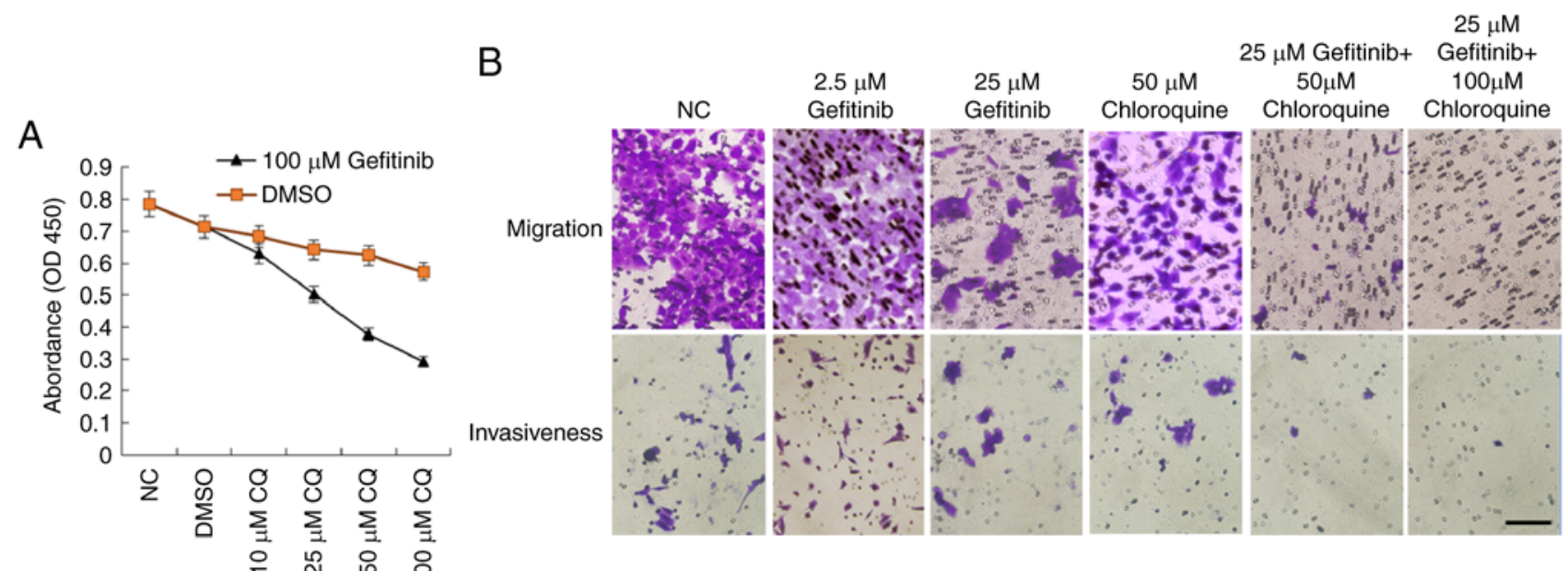

Chloroquine $(\mu \mathrm{M})$

NC
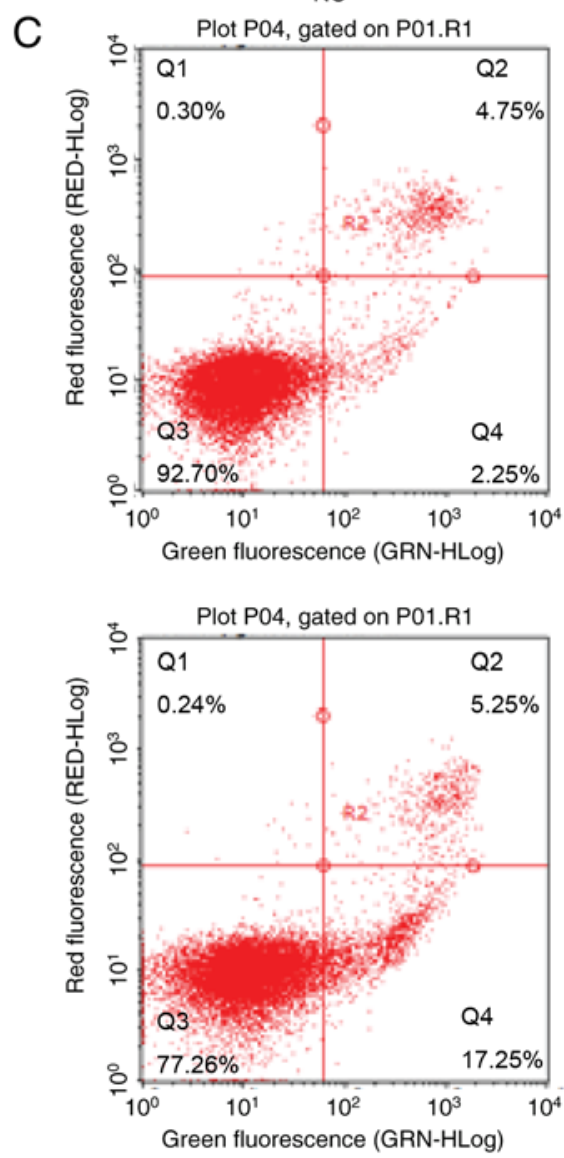

100
10
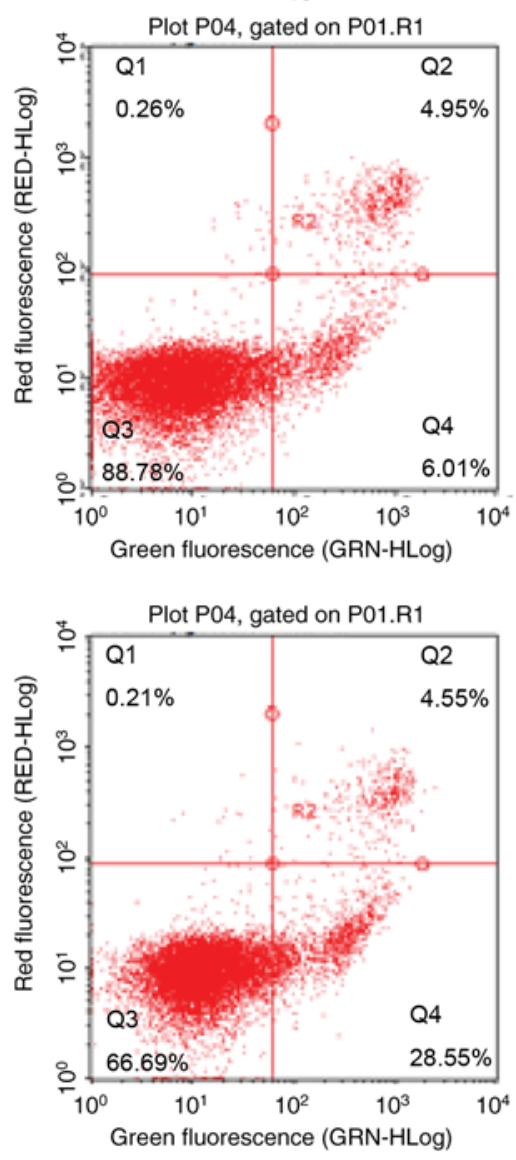

50

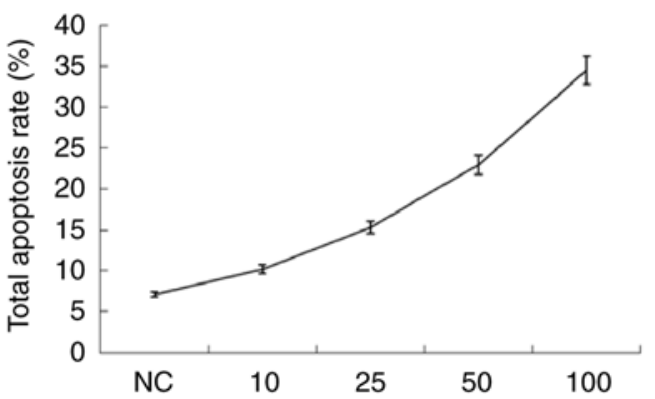

25

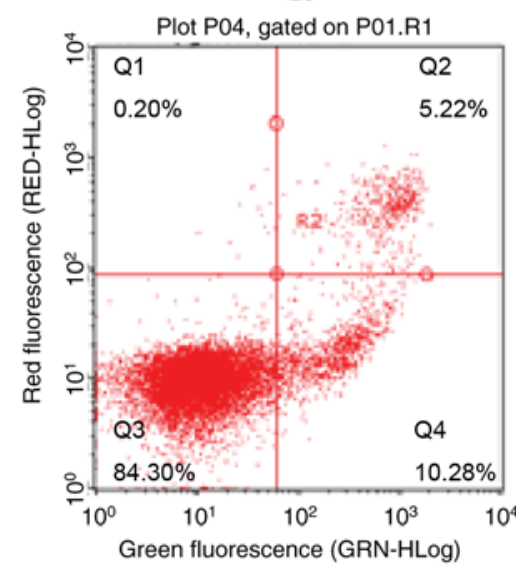

Concentration $(\mu \mathrm{M})$

Figure 4. Autophagy inhibition by chloroquine attenuates CSCC cell proliferation and promotes cell apoptosis. (A) A431 cells were treated with indicated concentrations of gefitinib and chloroquine or with DMSO and PBS as a control for $12 \mathrm{~h}$ and then the proliferation ability was detected by CCK-8 assays. (B) A431 cells were treated with indicated treatments for $12 \mathrm{~h}$ and then the invasive and migratory capacities were detected by Matrigel-coated or Matrigel-non-coated Transwell assays, respectively. Scale bar, $100 \mu \mathrm{m}$. (C) Total apoptosis rate of 431 cells following indicated treatments for $12 \mathrm{~h}$ was analyzed by flow cytometric analysis. GAPDH served as the loading control. CSCC, cutaneous squamous cell carcinoma. 
$\mathrm{D}$
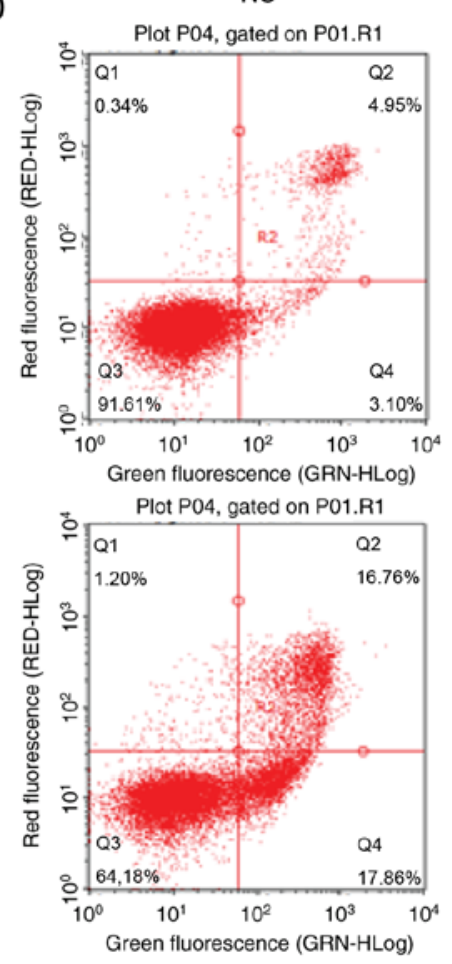

$100 \mu \mathrm{M}$ Gefitinib+ $25 \mu \mathrm{M}$ Chloroquine
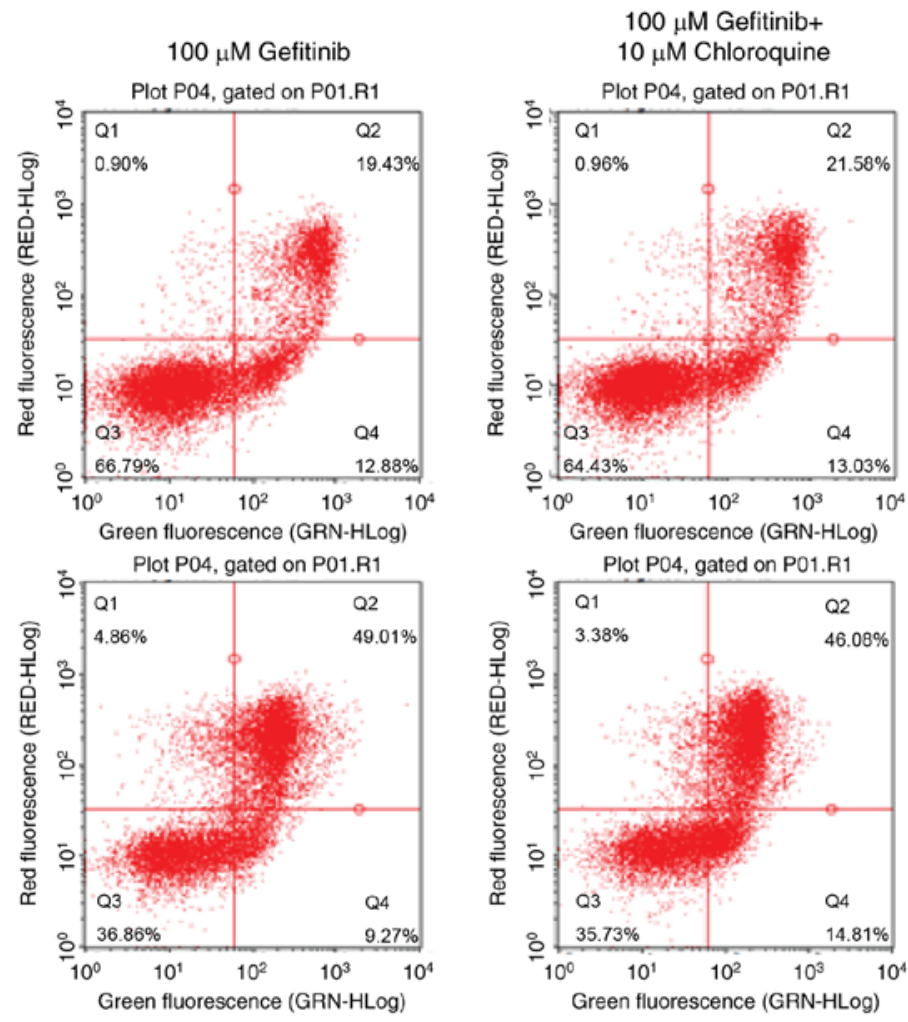

$100 \mu \mathrm{M}$ Gefitinib+

$50 \mu \mathrm{M}$ Chloroquine

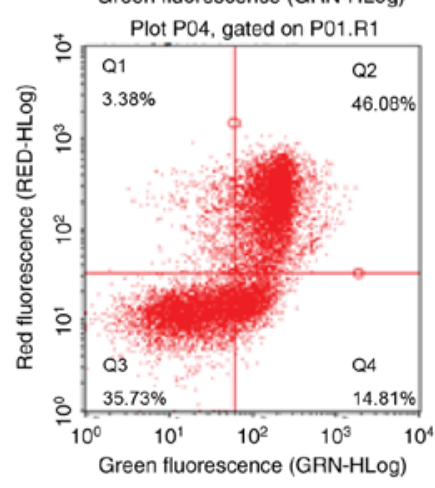

$100 \mu \mathrm{M}$ Gefitinib+ $100 \mu \mathrm{M}$ Chloroquine
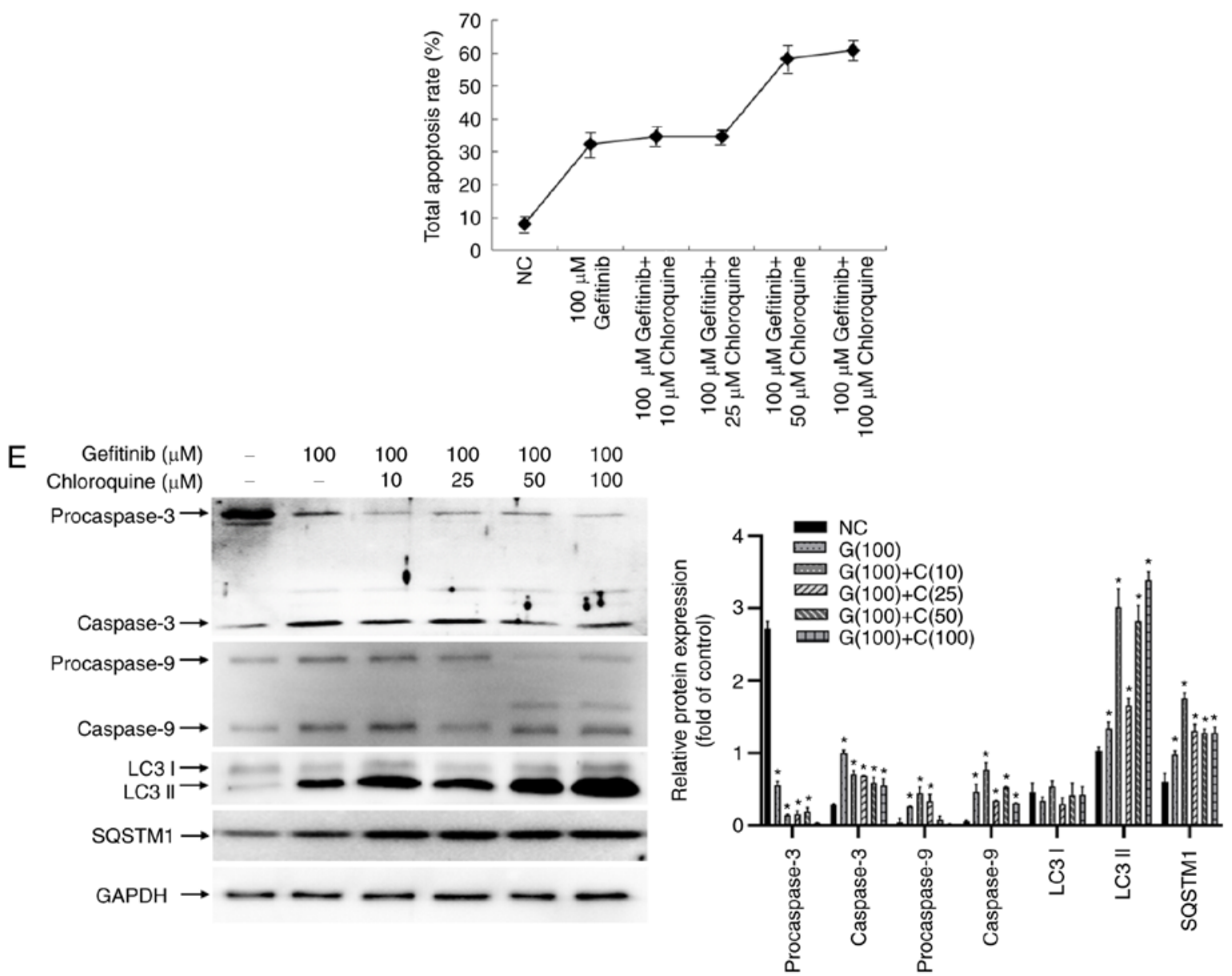

Figure 4. Continued. Autophagy inhibition by chloroquine attenuates CSCC cell proliferation and promotes cell apoptosis. (D) Total apoptosis rate of 431 cells following indicated treatments for $12 \mathrm{~h}$ was analyzed by flow cytometric analysis. (E) A431 cells were treated with indicated treatments for $12 \mathrm{~h}$ and then apoptosis and autophagy were monitored by detecting caspase-3, caspase-9, LC3-II, and SQSTM1 using western blotting analysis. GAPDH served as the loading control. ${ }^{*} \mathrm{P}<0.05$ vs. NC. CSCC, cutaneous squamous cell carcinoma. 
The anti-proliferation function of a specific drug for chemotherapy is determined by the combinatory effects of pathophysiological cellular processes promoted or suppressed by that drug, such as pro-apoptosis, anti-glycolysis or anti-autophagy. Since induction of apoptosis is a natural effect of gefinitib, gefinitib treatment must decrease the number of cells and influence the proliferation, migration, invasion, wound healing of tumor cells which is revealed by the decrease of the proliferation rate, especially in the case of the combined application of chloroquine to suppress pro-survival autophagy. Another question is whether this combinatorial treatment of drugs is harmful to normal cells? Owing to the natural effect of gefinitib designed for anti-EGFR treatment, the lower expression of EGFR in normal cells should markedly decrease the harmful effects induced by gefinitib.

There is a continuing need to focus on the clinical application of the concept of autophagy inhibition due to the ongoing question of whether inhibition or induction of autophagy improves the efficacy of anticancer therapy. One group revealed that chloroquine treatment induced apoptotic cell death in vitro and in vivo in nude mice. Conversely, chloroquine treatment did not elicit tumor suppression or prolong survival in immune-competent mice. This suggests that chloroquine-enhanced cell death in immune cells may compromise anticancer immune responses (25). Thus, in clinical applications of this type of therapy, it is important to consider the complex in vivo microenvironment and the impact on immune responses to avoid negative influences.

In summary, the present findings demonstrated that autophagy inhibition is an effective strategy for enhancing the sensitivity of tumor cells to anticancer treatment. Manipulating pro-survival autophagy by the combined application of chloroquine promotes gefitinib-induced apoptosis. These results support the combined use of EGFR and autophagy inhibitors for the treatment of UV-induced CSCC. This is a promising approach for improving the efficacy of EGFR inhibitors in cancer treatment. The results of the present study may have practical implications for EGFR-targeted therapeutic strategies in the near future.

\section{Acknowledgements}

Not applicable.

\section{Funding}

The present study was substantially supported by grants from the National Natural Science Foundation of China (grant nos. 81573076, 81172634 and 81772914; http://www.nsfc.gov. $\mathrm{cn} /$ ), a grant from the Guangdong Provincial Department of Science and Technology, China (grant no. 2016A030313738; http://www.gdstc.gov.cn/), a grant from the Science and Technology Program of Guangzhou, China (grant no. 201904010063; http://sop.gzsi.gov.cn/) and a grant from the School of Public Health of Southern Medical University, China (grant no. GW201612; http://web2.fimmu.com/phatm/).

\section{Availability of data and materials}

All data generated or analyzed during this study are included in this published article.

\section{Authors' contributions}

LZ and ZD conceived and designed the experiments. LZ, CO and HL performed the experiments. LZ, CO and HL analyzed the data. LZ and ZD wrote the manuscript. All authors read and approved the manuscript and agree to be accountable for all aspects of the research in ensuring that the accuracy or integrity of any part of the work are appropriately investigated and resolved.

\section{Ethics approval and consent to participate}

The present study was approved by the Institutional Review Board of Nanfang Hospital, affiliated to Southern Medical University. All patients provided written informed consent for the use of surgical samples.

\section{Patient consent for publication}

Not applicable.

\section{Competing interests}

The authors declare that they have no competing interests.

\section{References}

1. Lomas A, Leonardi-Bee $\mathrm{J}$ and Bath-Hextall F: A systematic review of worldwide incidence of nonmelanoma skin cancer. $\mathrm{Br}$ J Dermatol 166: 1069-1080, 2012.

2. El-Abaseri TB, Fuhrman J, Trempus C, Shendrik I, Tennant RW and Hansen LA: Chemoprevention of UV light-induced skin tumorigenesis by inhibition of the epidermal growth factor receptor. Cancer Res 65: 3958-3965, 2005.

3. Kyriakis JM and Avruch J: Protein kinase cascades activated by stress and inflammatory cytokines. Bioessays 18: 567-577, 1996.

4. Rosette $C$ and Karin M: Ultraviolet light and osmotic stress: Activation of the JNK cascade through multiple growth factor and cytokine receptors. Science 274: 1194-1197, 1996.

5. Lewis CM, Glisson BS, Feng L, Wan F, Tang X, Wistuba II, El-Naggar AK, Rosenthal DI, Chambers MS, Lustig RA and Weber RS: A phase II study of gefitinib for aggressive cutaneous squamous cell carcinoma of the head and neck. Clin Cancer Res 18: 1435-1446, 2012.

6. Alam M and Ratner D: Cutaneous squamous-cell carcinoma. N Engl J Med 344: 975-983, 2001.

7. Chang CY, Kuan YH, Ou YC, Li JR, Wu CC, Pan PH, Chen WY, Huang HY and Chen CJ: Autophagy contributes to gefitinib-induced glioma cell growth inhibition. Exp Cell Res 327: 102-112, 2014

8. Merlino GT, Xu YH, Ishii S, Clark AJ, Semba K, Toyoshima K, Yamamoto T and Pastan I: Amplification and enhanced expression of the epidermal growth factor receptor gene in A431 human carcinoma cells. Science 224: 417-419, 1984.

9. Degenhardt K, Mathew R, Beaudoin B, Bray K, Anderson D, Chen G, Mukherjee C, Shi Y, Gélinas C, Fan Y, et al: Autophagy promotes tumor cell survival and restricts necrosis, inflammation, and tumorigenesis. Cancer Cell 10: 51-64, 2006.

10. Yang ZJ, Chee CE, Huang $S$ and Sinicrope FA: The role of autophagy in cancer: therapeutic implications. Mol Cancer Ther 10: 1533-1541, 2011.

11. Klionsky DJ, Abdalla FC, Abeliovich H, Abraham RT, Acevedo-Arozena A, Adeli K, Agholme L, Agnello M, Agostinis P, Aguirre-Ghiso JA, et al: Guidelines for the use and interpretation of assays for monitoring autophagy. Autophagy 8: 445-544, 2012.

12. Zhou L, Wang Y, Zhou M, Zhang Y, Wang P, Li X, Yang J, Wang $H$ and Ding Z: HOXA9 inhibits HIF- $1 \alpha$-mediated glycolysis through interacting with CRIP2 to repress cutaneous squamous cell carcinoma development. Nat Commun 9: 1480, 2018. 
13. Livak KJ and Schmittgen TD: Analysis of relative gene expression data using real-time quantitative PCR and the 2(-Delta Delta C(T)) method. Methods 25: 402-408, 2001.

14. Feoktistova M, Geserick P and Leverkus M: Crystal violet assay for determining viability of cultured cells. Cold Spring Harbor Protocols 2016: pdb.prot087379, 2016.

15. Thomé MP, Filippi-Chiela EC, Villodre ES, Migliavaca CB, Onzi GR, Felipe KB and Lenz G: Ratiometric analysis of acridine orange staining in the study of acidic organelles and autophagy. J Cell Sci 129: 4622-4632, 2016.

16. Lynch TJ, Bell DW, Sordella R, Gurubhagavatula S Okimoto RA, Brannigan BW, Harris PL, Haserlat SM, Supko JG, Haluska FG, et al: Activating mutations in the epidermal growth factor receptor underlying responsiveness of non-small-cell lung cancer to gefitinib. N Engl J Med 350: 2129-2139, 2004.

17. Ciardiello $\mathrm{F}$ and Tortora G: EGFR antagonists in cancer treatment. N Engl J Med 358: 1160-1174, 2008.

18. Johnston JB, Navaratnam S, Pitz MW, Maniate JM, Wiechec E, Baust H, Gingerich J, Skliris GP, Murphy LC and Los M: Targeting the EGFR pathway for cancer therapy. Curr Med Chem 13: 3483-3492, 2006.

19. Bethune G, Bethune D, Ridgway $\mathrm{N}$ and $\mathrm{Xu} Z$ : Epidermal growth factor receptor (EGFR) in lung cancer: An overview and update. J Thorac Dis 2: 48-51, 2010.

20. Henson ES and Gibson SB: Surviving cell death through epidermal growth factor (EGF) signal transduction pathways: Implications for cancer therapy. Cell Signal 18: 2089-2097, 2006.

21. Kobayashi S, Boggon TJ, Dayaram T, Jänne PA, Kocher O, Meyerson M, Johnson BE, Eck MJ, Tenen DG and Halmos B: EGFR mutation and resistance of non-small-cell lung cancer to gefitinib. N Engl J Med 352: 786-792, 2005.
22. Galluzzi L, Aaronson SA, Abrams J, Alnemri ES, Andrews DW, Baehrecke EH, Bazan NG, Blagosklonny MV, Blomgren K, Borner C, et al: Guidelines for the use and interpretation of assays for monitoring cell death in higher eukaryotes. Cell Death Differ 16: 1093-1107, 2009.

23. Galluzzi L, Pietrocola F, Amaravadi RK, Bravo-San Pedro JM, Amaravadi RK, Baehrecke EH, Cecconi F, Codogno P, Debnath J, Gewirtz DA, et al: Autophagy in malignant transformation and cancer progression. EMBO J 34: 856-880, 2015.

24. Dragowska WH, Weppler SA, Wang JC, Wong LY, Kapanen AI, Rawji JS, Warburton C, Qadir MA, Donohue E, Roberge M, et al: Induction of autophagy is an early response to gefitinib and a potential therapeutic target in breast cancer. PLoS One 8: e76503, 2013.

25. Masuelli L, Granato M, Benvenuto M, Mattera R, Bernardini R, Mattei M, d'Amati G, D'Orazi G, Faggioni A, Bei R and Cirone M: Chloroquine supplementation increases the cytotoxic effect of curcumin against Her $2 /$ neu overexpressing breast cancer cells in vitro and in vivo in nude mice while counteracts it in immune competent mice. Oncoimmunology 6: e1356151, 2017.

This work is licensed under a Creative Commons Attribution-NonCommercial-NoDerivatives 4.0 International (CC BY-NC-ND 4.0) License. 